\title{
PROFESSORES E SUAS TECNOLOGIAS: UMA CULTURA DOCENTE EM AÇÃO
}

\author{
TIAGO DZIEKANIAK FIGUEIREDO' \\ ORCID: https://orcid.org/0000-0001-6383-7252 \\ SHEYLA COSTA RODRIGUES" \\ ORCID: https://orcid.org/000-0002-9402-7719
}

I Universidade Federal da Grande Dourados, Dourados, MS, Brasil.

II Universidade Federal do Rio Grande, Rio Grande, RS, Brasil.

Tiago D. Figueiredo - Doutor em Educação pela Universidade Federal de Pelotas - UFPEL. Professor da Universidade Federal da Grande Dourados - UFGD. Líder do Grupo de Pesquisa Tecnologias na Educação Matemática - GPTEM/CNPq. E-mail:<tiagofigueiredo@ufgd.edu.br >.

Sheyla C. Rodrigues - Doutora em Informática na Educação pela Universidade Federal do Rio Grande do Sul - UFRGS. Professora da Universidade Federal do Rio Grande - FURG. E-mail:< sheylarodrigues@furg.br >.

RESUMO: O artigo apresenta os resultados de uma pesquisa realizada com 18 professores de matemática, que são alunos ou egressos do Programa de Pós-Graduação em Educação em Ciências da Universidade Federal do Rio Grande - FURG. Com suporte teórico na Biologia do Conhecer, trazemos a análise de três discursos, utilizando a técnica do Discurso do Sujeito Coletivo, na qual é possível observar a cultura destes professores quanto à organização e a particularização do seu fazer, no uso das tecnologias digitais, uma vez que estas estão cada vez mais presentes nos espaços educativos, com potencial para transformar o ensinar e o aprender, bem como a compreensão dos professores sobre a necessidade de uma maior apropriação técnica e a importância de aceitá-las e usá-las pedagogicamente. Palavras-chave: Professores. Matemática. Tecnologias digitais. Recurso pedagógico.

\section{TEACHER AND THEIR TECHNOLOGIES: A TEACHING CULTURE IN ACTION}

ABSTRACT: The article presents the results of a survey of 18 math teachers, students or graduates of the Graduate Program in Science Education from the Federal University of Rio Grande - FURG. With theoretical support in the Biology of Knowledge, we bring the analysis of three speeches, using the technique of the Collective Subject Discourse, where you can observe 
the culture of these teachers for the organization and the particularization of their doing, the use of digital technologies, as these are increasingly present in the educational spaces, with the potential to transform teaching and learning, and teachers' understanding of the need for greater technical ownership and the importance of accepting them and use them pedagogically.

Keywords: Teachers. Mathematic. Digital technologies. Educational resource.

\section{INTRODUĈ̣̃O}

Ao fazermos ciência a fazemos como observadores explicando o que observamos em nosso observar. Para Maturana (2014, p. 134), "como observadores, somos seres humanos. Nós, seres humanos, já nos encontramos na situação de observadores observando quando começamos a observar nosso observar em nossa tentativa de descrever e explicar o que fazemos.".

Como observadores, vivemos uma história de transformações de condutas, por isso, podemos descrever estas condutas que resultam de interações recorrentes. Neste observar, foi organizado este trabalho, no qual se buscou compreender que cultura docente em ação, emerge dos discursos coletivos dos professores de Matemática, alunos ou egressos do Programa de Pós-Graduação em Educação em Ciências - PPGEC, da Universidade Federal do Rio Grande - FURG.

O estudo foi desenvolvido com base na análise de três discursos coletivos, e os resultados apresentados vão ao encontro do objetivo da pesquisa, provocando um entrelaçamento entre os conceitos de cultura (MATURANA, 2011) e cultura docente em ação (TARDIF, 2014).

No estudo problematizamos o uso dos recursos digitais na ação dos professores por compreendermos que lidar com diferentes dispositivos criam situações que podem gerar aprendizagens. A diversificação e o acesso aos mesmos, atualmente, ocorrem de forma muito rápida, mostrando que mecanismos de consulta, por exemplo, são capazes de dinamizar as aulas e que a educação pode acontecer em todo lugar, não mais limitada aos espaços educativos formais (BETTEGA, 2004). 


\section{METODOLOGIA}

Para compreender o fenômeno a ser explicado encontramos suporte teórico na Biologia do Conhecer, de Humberto Maturana e Francisco Varela, assumindo-nos como o observador implicado no próprio fenômeno a ser explicado, para construir uma explicação científica, ou seja, uma proposição que possa reformular ou recriar uma nova observação sobre o fenômeno (MATURANA, 2011, MATURANA; VARELA, 2010).

Como nossa intenção era conhecer o trabalho que estes alunos e egressos realizam na escola ou na universidade não bastava que estes professores fossem estudantes do PPGEC, mas também que esses atuassem na rede básica de ensino ou na universidade. $\mathrm{Na}$ consulta que realizamos na Plataforma Lattes, foi possível identificar que dos 23 sujeitos, 18 são professores atuantes em sala de aula.

Optamos pela metodologia qualitativa (LANKSHEAR; KNOBEL, 2008), porque esta nos auxilia a compreender como as pessoas experimentam, interpretam e atuam. Assim, investigar um grupo de professores que são alunos ou egressos e, por isso, se encontram em processos de formação contínua e continuada, no nosso entender poderá nos ajudar a compreender a cultura docente em ação desses professores no uso das tecnologias digitais.

Para conhecer seus discursos sobre as tecnologias digitais elaboramos um questionário, através de um formulário eletrônico no Google Drive, ${ }^{1}$ enviado aos 18 professores que atendiam ao nosso critério de inclusão. O formulário foi escolhido por ser uma ferramenta de fácil acesso, uma vez que foi enviado por e-mail e os colaboradores poderiam responder conforme tivessem disponibilidade de tempo.

O formulário era composto por três questões abertas, permitindo que os professores relatassem suas práticas no uso das tecnologias digitais e como estas vem sendo realizadas em seus espaços educativos, conforme Quadro 1. 


\section{QUADRO 1. Questões de pesquisa}

- Ao longo dos anos, são visíveis os avanços provocados pela ciência e a tecnologia. Ao transitarmos pelos espaços educativos, e compreendendo a escola como um espaço integrante desta sociedade, também percebemos mudanças. Dentre estas mudanças, destacamos a inserção de diferentes tecnologias digitais (computadores, netbooks, lousas digitais, projetores multimídias, entre outras) cada vez mais presentes nesses espaços. Nos espaços educativos que você transita é possível perceber estas mudanças? Como ocorreu a inserção destas tecnologias? De que forma elas se situam em seu fazer docente?

- $\quad$ Pierre Lévy, um estudioso da tecnologia expressa em seus livros que os alunos, por serem nativos da era digital, possuem uma grande facilidade no manuseio dos recursos tecnológicos, implicando a necessidade de que os professores também sejam conhecedores destes recursos. Em seus estudos defende que o conhecimento deve ser construído através de um processo de colaboração, apontando a necessidade da capacitação do professor, visto que só podemos ensinar aquilo que sabemos. Nesta perspectiva, como o professor pode agir para fazer parte da cultura digital possibilitando que as tecnologias digitais sejam utilizadas de forma pedagógica?

- Pierre Lévy salienta que as ferramentas tecnológicas necessitam estar a serviço da educação, potencializando espaços para uma participação efetiva dos alunos no processo de ensinar e aprender. De que forma, no seu entender, os artefatos tecnológicos potencializam aprendizagens, tanto de alunos quanto de professores, em um processo de colaboração mútua?

\section{Fonte: 0 autor.}

Como nossa intenção não era quantificar o que diziam os colaboradores do estudo, e sim conhecer seus discursos singulares para entender como pensa este coletivo escolhemos como metodologia de análise o Discurso do Sujeito Coletivo (DSC) de Lefèvre e Lefèvre (2005a, 2005b, 2010), que apresentam uma proposta de análise a partir de discursos coletivos. Para os autores a técnica nos ajuda a organizar dados qualitativos na medida em que permite, através de procedimentos sistemáticos e padronizados, agregar depoimentos sem reduzi-los a quantidades.

Para que seja possível a construção de um DSC, é necessário identificar quatro operadores, que são as Expressões-Chave $(\mathrm{ECH})$, 
as Ideias Centrais (IC), as Ancoragens (AC) e finalmente os Discursos do Sujeito Coletivo (DSC). No Quadro 2, podemos identificar o significado de cada um dos operadores.

QUADRO 2. Os operadores do DSC

- As ECH, são trechos selecionados do material coletado, que descrevem o conteúdo. ECH são trechos selecionados do material verbal de cada depoimento, que melhor descrevem seu conteúdo. Podem ser trechos contínuos ou descontínuos que o pesquisador deve selecionar que revelam a teoria subjacente. Ao selecionar as $\mathrm{ECH}$, devemos retirar do discurso tudo o que for irrelevante, ficando apenas com partes que revelam a essência do pensamento, de forma literal ao como ele aparece.

- IC são fórmulas sintéticas que descrevem o(s) sentido(s) presentes nos depoimentos de cada resposta e também nos conjuntos de respostas de diferentes indivíduos, que apresentam sentido semelhante ou complementar. São expressões linguísticas que expressam de forma mais objetiva o sentido ou os sentidos das ECH de cada discurso analisado. Em síntese as ECH são expressivas, literais enquanto as IC são abstratas, conceituais.

- $\mathrm{AC}$ são como as IC, fórmulas sintéticas que descrevem não os sentimentos, mas as ideologias, os valores, as crenças, presentes no material verbal das respostas individuais ou das agrupadas, sob a forma de afirmações genéricas destinadas a enquadrar situações particulares. Na metodologia do DSC, considera-se que existem AC apenas quando há, no material verbal, marcas discursivas explícitas dessas afirmações genéricas.

- DSC são a reunião das ECH presentes nos depoimentos, que têm IC e/ou AC de sentido semelhante ou complementar.

Fonte: Lefèvre e Lefèvre (2005b).

Para Lefèvre e Lefèvre (2000, p. 19), “O DSC é, assim, uma estratégia metodológica com vistas a tornar mais clara uma dada representação social e o conjunto das representações que conforma um dado imaginário". Por meio de discursos, foi possível visualizar de forma mais clara sem a necessidade de interpretação de tabelas e gráficos, como os professores colaboradores usam as tecnologias digitais em seu fazer.

Para construirmos os discursos, fizemos uso de duas tabelas, as quais denominamos Instrumentos de Análise 1 e 2. Na 
primeira tabela (Quadro 3), composta por três colunas, copiamos integralmente as falas dos professores na primeira coluna $(\mathrm{ECH})$. Para identificar as IC, utilizamos o recurso de cor destacando o essencial do conteúdo explicitado pelos professores nas ECH. As IC são descrições do sentido presente nas ECH, não interpretações. Elas também possibilitam identificar as teorias, as ideologias, os conceitos e as hipóteses dos participantes do estudo, que são representadas pelas AC.

QUADRO 3. Recorte do Instrumento de Análise do Discurso 1 - IAD1

\begin{tabular}{|c|c|c|}
\hline Expressões-Chave (ECH) & Ideias centrais (IC) & $\begin{array}{c}\text { Ancoragens } \\
\text { (AC) }\end{array}$ \\
\hline $\begin{array}{l}\text { Hoje, com um maior } \\
\text { conhecimento sobre o uso do } \\
\text { computador e todos as demais } \\
\text { tecnologias, não sobrevivo sem } \\
\text { as mesmas. Só não sei usar nada } \\
\text { mesmo sobre lousas digitais, } \\
\text { pois não tive tal oportunidade de } \\
\text { aquisição deste conhecimento. } \\
\text { Ainda chego lá. Este aprendizado } \\
\text { fui adquirindo no dia a dia pela } \\
\text { necessidade mesmo. Uma ou outra } \\
\text { vez recebi informações para tal } \\
\text { uso. No meu uso sobre o fazer } \\
\text { docente, gosto de pesquisar na } \\
\text { internet; e sempre que necessito } \\
\text { de informações rápidas, busco-as } \\
\text { através deste mecanismo }\end{array}$ & $\begin{array}{l}\text { - Maior } \\
\text { conhecimento sobre } \\
\text { as tecnologias } \\
\text { - Necessidade de } \\
\text { usar as tecnologias } \\
\text { - Falta de formação } \\
\text { - Aprender pela } \\
\text { necessidade } \\
\text { - Utilização das } \\
\text { tecnologias }\end{array}$ & $\begin{array}{l}\text { Formação } \\
\text { do } \\
\text { professor }\end{array}$ \\
\hline $\begin{array}{l}\text { Nas escolas que transitam as } \\
\text { tecnologias digitais já estão } \\
\text { presentes, mas ainda falta } \\
\text { formação para os professores. } \\
\text { Esta formação deve vir } \\
\text { compartilhada pelo docente para } \\
\text { que ele sinta-se participe desta. }\end{array}$ & $\begin{array}{l}\text { - Falta de } \\
\text { oportunidades para } \\
\text { formação } \\
\text { - Formação pautada } \\
\text { nas necessidades dos } \\
\text { professores }\end{array}$ & $\begin{array}{l}\text { Formação } \\
\text { do } \\
\text { professor }\end{array}$ \\
\hline
\end{tabular}


Há tecnologias digitais presentes em todas as escolas que atualmente atuo, seja pela própria disponibilização das mesmas pela escola ou trazidas pelos alunos. São celulares, tablets, netbooks, internet wifi, laboratórios de informática. Mas esta tecnologia somente é utilizada quando há uma proposta pedagógica da escola, pois assim há manutenção dos equipamentos e possibilidade de construção de um trabalho coletivo dos professores. Elas se fazem presentes em meu fazer docente ao desenvolvermos as pesquisas dos projetos de aprendizagem e ao preparar os materiais para as aulas.

No entanto, percebo que as tecnologias digitais ainda não são utilizadas para a construção dos conhecimentos escolares, visto que a metodologia de trabalho com projetos é trabalha de forma pontual na escola.
- Presença das tecnologias

- Necessidade de uma proposta pedagógica

- Trabalho coletivo dos professores

- Utilização das tecnologias

- Uso da tecnologia pela tecnologia
Dar-se

conta

Fonte: 0 autor.

O passo seguinte foi agrupar as IC e as AC de mesmo sentido, de sentido equivalente ou de sentido complementar em uma nova tabela. Os DSC foram construídos através do agrupamento das $\mathrm{ECH}$ dos diferentes depoimentos em que as IC mostravam sentido conforme o Quadro 4. 
QUADRO 4. Recorte do Instrumento de Análise do Discurso 2 - IAD2

\begin{tabular}{|c|c|}
\hline Expressões-Chave (ECH) & Discurso Coletivo \\
\hline $\begin{array}{l}\text { um maior conhecimento sobre o uso do } \\
\text { computador e todos as demais tecnologias } \\
\text { Só não sei usar nada mesmo sobre lousas digitais, } \\
\text { pois não tive tal oportunidade de aquisição deste } \\
\text { conhecimento } \\
\text { ainda falta formação para os professores } \\
\text { não sobrevivo sem as mesmas. } \\
\text { necessidade do professor se adequar as mudanças } \\
\text { que vem ocorrendo no mundo } \\
\text { pedido dos professores que necessitam delas para } \\
\text { desenvolver seu trabalho } \\
\text { Este aprendizado fui adquirindo no dia a dia pela } \\
\text { necessidade mesmo. } \\
\text { gosto de pesquisar na internet; e sempre que } \\
\text { necessito de informações rápidas, busco-as através } \\
\text { deste mecanismo } \\
\text { quando é necessário e/ou útil seu uso } \\
\text { Elas se fazem presentes em meu fazer docente } \\
\text { ao desenvolvermos as pesquisas dos projetos de } \\
\underline{\text { aprendizagem e ao preparar os materiais para as }} \\
\text { aulas } \\
\text { se situam no meu cotidiano na escola e fora dela } \\
\text { presença ainda tímida, mas de forma crescente o } \\
\text { uso de computadores e projetores multimídias } \\
\text { Costume usar as todas as tecnologias disponíveis } \\
\text { na escola desde que se façam necessários no } \\
\text { planejamento } \\
\text { Grande parte das vezes, preparamos nossos } \\
\text { mo materias em casa, em power point, vídeo, etc e } \\
\text { pedagógicas. } \\
\text { reproduzimos na sala de aula ou utilizamos a s } \\
\text { redes sociais para compartilhar com os alunos } \\
\text { principalmente os computadores e o multimídia } \\
\text { os quais particularmente uso mais quando quero } \\
\text { trabalhar com jogos ou até mesmo fazer uma } \\
\text { apresentação de slides ou passar um vídeo para os } \\
\text { alunos }\end{array}$ & $\begin{array}{l}\text { Percebo a todo instante a inserção } \\
\text { de tecnologias na escola. É visivel a } \\
\text { inserção de outras que não aquelas que } \\
\text { estavamos acostumados a ter como o } \\
\text { quadro e o giz. Há tecnologias digitais } \\
\text { presentes em todas as escolas, seja pela } \\
\text { própria disponibilização das mesmas } \\
\text { pela escola ou trazidas pelos alunos } \\
\text { entre elas, celulares, netbooks, internet } \\
\text { wifi, laboratórios de informática, } \\
\text { lousas digitais, aparelhos multimídia } \\
\text { e recentemente os tablets. Elas se } \\
\text { fazem presentes em meu fazer docente } \\
\text { ao desenvolvermos as pesquisas } \\
\text { dos projetos de aprendizagem e ao } \\
\text { preparar os materiais para as aulas, } \\
\text { como ferramental de apoio e como } \\
\text { dispositivos capazes de produzir } \\
\text { novas significações pedagógicas. } \\
\text { Gosto de pesquisar na internet; e } \\
\text { sempre que necessito de informações } \\
\text { rápidas, busco-as através deste } \\
\text { mecanismo. Grande parte das vezes, } \\
\text { preparamos nossos materiais em } \\
\text { casa, em powerpoint, vídeo, etc. e } \\
\text { reproduzimos na sala de aula ou } \\
\text { utilizamos as redes sociais para } \\
\text { compartilhar com os alunos. No meu } \\
\text { fazer docente elas se situam como } \\
\text { instrumentos que potencializam a ação } \\
\text { de ensinar, mas mudança pedagógica } \\
\text { pouco ocorre. As significações } \\
\text { pedagógicas compreendem o encontro } \\
\text { das narrativas em rede com as } \\
\text { experimentações em sala de aula, de } \\
\text { modo a articular o que é teorizado e } \\
\text { proposto metodologicamente. Aprendi } \\
\text { no dia a dia pela necessidade mesmo, } \\
\text { mas ainda falta formação para os } \\
\text { professores e um maior conhecimento } \\
\text { sobre o uso do computador e todos } \\
\text { as demais tecnologias, bem como a } \\
\text { necessidade do professor se adequar } \\
\text { as mudanças que vem ocorrendo } \\
\text { no mundo para a construção de um } \\
\text { trabalho coletivo. Não sobrevivo sem } \\
\text { as mesmas. }\end{array}$ \\
\hline
\end{tabular}

Fonte: 0 autor. 
Nesta construção, para que seja proporcionada a coesão textual, utilizamos conectivos para sequenciar as ECH, o que, segundo a técnica, é permitido.

\section{ANALISANDO E DISCUTINDO OS DISCURSOS COLETIVOS}

Analisando as respostas dos questionários pelo operar da técnica do DSC, emergiram três discursos coletivos: "As tecnologias digitais no fazer docente", "O uso pedagógico das tecnologias digitais" e "O potencial das tecnologias digitais para aprendizagens colaborativas".

Os três discursos são apresentados e analisados separadamente, não porque os entendemos como aspectos isolados da ação docente, mas por compreendermos que expressam as reflexões dos professores sobre aspectos que emanam das coordenações de coordenações de ações e emoções do seu fazer. De acordo com Lefèvre e Lefèvre (2005b, p. 16), o discurso coletivo expressa o “[...] eu sintático que, ao mesmo tempo em que sinaliza a presença de um sujeito individual do discurso, expressa uma coletividade".

\section{AS TECNOLOGIAS DIGITAIS NO FAZER DOCENTE}

No transitar pelos espaços educativos da rede pública municipal da cidade de Rio Grande (RS), foi perceptível a grande quantidade de recursos digitais disponíveis para o trabalho dos professores como computadores, netbooks, projetores, câmeras fotográficas digitais, entre outros. A presença destes recursos ajudanos a compreender como a escola, que faz parte de uma sociedade, se modifica por influência do desenvolvimento tecnológico.

Este desenvolvimento faz com que até mesmo os mais remotos lugares sem condições básicas, como acesso à água potável ou à energia elétrica, transformem-se cotidianamente por meio do fenômeno da globalização oriunda dos recursos tecnológicos (SANCHO, 2006).

Deste modo, entendemos que disponibilizar os recursos tecnológicos é um importante passo para que professores e alunos os utilizem em suas salas de aula. Entretanto, não haverá significação pedagógica se estas tecnologias não forem usadas como ferramentas que potencializem os processos de aprendizagem.

Ainda segundo Tardif e Lessard (2013, p. 45), o trabalho docente será planejado e passível de modificação pela necessidade de alterações, tendo em vista as demandas cotidianas porque "[...] o trabalho dos professores possui justamente aspectos formais e aspectos informais, 
e que se trata, portanto, ao mesmo tempo, de um trabalho flexível e codificado, controlado e autônomo, determinado e contingente [...]".

Assim, planejar significa manter laços estreitos com os objetivos e com os programas escolares. Devem ser considerados o conhecimento sobre os alunos, as atividades desenvolvidas anteriormente e posteriormente, a natureza do conteúdo a ser ensinado, as atividades de ensino e a diversidade de recursos existentes na escola.

No discurso coletivo "As tecnologias digitais no fazer docente" (DSC1), é possível identificar como as tecnologias digitais chegam às escolas e a forma como são inseridas nestes ambientes e no fazer dos professores.

Percebo a todo instante a inserção de tecnologias na escola. É visivel a inserção de outras que não aquelas que estávamos acostumados a ter como o quadro e o giz. Há tecnologias digitais presentes em todas as escolas, seja pela própria disponibilização das mesmas pela escola ou trazidas pelos alunos, entre elas, celulares, netbooks, internet wifi, laboratórios de informática, lousas digitais, aparelhos multimidia e recentemente os tablets. Elas se fazem presentes em men fazer docente ao desenvolvermos as pesquisas dos projetos de aprendizagem e ao preparar os materiais para as aulas, como ferramental de apoio e como dispositivos capazes de produzir novas significações pedagógicas. Gosto de pesquisar na internet; e sempre que necessito de informações rápidas, busco-as através deste mecanismo. Grande parte das vezes, preparamos nossos materiais em casa, em powerpoint, vídeo e reproduzimos na sala de aula ou utilizamos as redes sociais para compartilhar com os alunos. No men fazer docente elas se situam como instrumentos que potencializam a ação de ensinar, mas mudança pedagógica pouco ocorre. As significações pedagógicas compreendem o encontro das narrativas em rede com as experimentações em sala de aula, de modo a articular o que é teorizado e proposto metodologicamente. Aprendi no dia a dia pela necessidade mesmo, mas ainda falta formação e um maior conhecimento sobre o uso do computador e todos as demais tecnologias, bem como a necessidade do professor se adequar as mudanças que vem ocorrendo no mundo para a construção de um trabalho coletivo. Não sobrevivo sem as mesmas.

\section{DSC1 - As tecnologias digitais no fazer docente}

O discurso coletivo é um indicador de que os professores percebem as tecnologias digitais cada vez mais presentes em seus espaços educativos e como estes recursos se diversificam a todo instante, seja porque as escolas os disponibilizam ou porque são os próprios alunos que as inserem, em decorrência de um viver imerso no mundo digital. 
Pensar na diversificação das tecnologias, ao longo dos anos, vem ao encontro do que Orofino (2005) afirma sobre o desenvolvimento da tecnologia. Para a autora, a euforia econômica do mercado faz com que os contextos social e cultural se modifiquem de acordo com as novidades que surgem a cada dia, as quais potencializam o desejo pelo consumo de diferentes equipamentos.

Ao reportarem sobre a chegada das tecnologias nos espaços educativos, os educadores mostram que também compreendem o quadro e o giz como tecnologias, ou seja, como ferramentas que auxiliam o desenvolvimento de sua ação. No fragmento do discurso "É visível a inserção de outras que não aquelas que estávamos acostumados a ter como o quadro e o giz", emerge um mundo de significados para a palavra tecnologia. Embora estas tecnologias não sejam as digitais, os professores também tiveram que se adaptar e aprender a usá-las como ferramentas de trabalho. Para isso, passaram por um período de conhecimento e adaptação, assim como agora necessitam fazer com os recursos digitais para que possam utilizá-los de maneira pedagógica.

A adaptação ao uso de qualquer recurso é fruto de um processo evolutivo e natural, uma vez que, aos poucos, os quadros verdes estão sendo substituídos por quadros brancos, os quais, por sua vez, também estão sendo trocados pelas lousas digitais. O giz também foi trocado pelas canetas de tinta e consequentemente pelas canetas digitais. Os retroprojetores aos poucos dão espaço aos projetores multimídia; os mimeógrafos, às máquinas reprográficas; os computadores, aos netbooks, e estes, consequentemente, aos tablets.

O coletivo expressa, no discurso, a aceitação das tecnologias digitais, e evidencia que estes artefatos estão presentes em seu fazer docente, com possibilidade de potencializar o ato pedagógico. Entretanto, mesmo percebendo que fazem usos das tecnologias digitais para preparar suas aulas ou até mesmo na busca por informações junto com seus alunos, ainda sentem a necessidade de aprimorar seus conhecimentos em relação ao seu uso e reconhecem que poucas mudanças pedagógicas ocorrem em função de pouca apropriação (DSC 1).

No discurso coletivo, deixam transparecer isso quando dizem "no meu fazer docente elas se situam como instrumentos que potencializam a ação de ensinar, mas mudança pedagógica pouco ocorre" (DSC 1). Porque dizem isso? O que os leva a fazer tal afirmação? Nesse sentido, Pablos (2006) nos auxilia a pensar sobre tais questionamentos ao expressar que muitos professores dispõem de habilidades suficientes para se sentir cômodos com o uso do computador e internet, mas muitos ainda têm dúvidas sobre a melhoria pedagógica real que sua utilização pode significar. 
Este processo de identificar que poucas mudanças pedagógicas acontecem é entendido por nós como o dar-se conta sobre sua atuação pedagógica. Podemos ainda pensar que a reflexão sobre a própria ação é um importante passo para o desenvolvimento de outra forma de ensinar e aprender, ou seja, a reflexão sobre a ação é geradora de uma nova rede de conversação que forma culturas. Entendemos que uma cultura é "uma rede fechada de conversações que constitui e define uma maneira de convivência humana como uma rede de coordenações de emoções e ações" (MATURANA, 2011, p. 33).

Thurler (2001, p. 89) corrobora este conceito de cultura, quando expressa que "cada escola tem sua própria atmosfera, suas próprias vibrações, que a tornam única”, evidenciando que uma cultura é construída em um processo contínuo de aprendizagem, mesmo que muitas vezes inconsciente, por meio dos sujeitos que constituem este espaço.

Entender a própria ação e dar-se conta das infinitas possibilidades que o uso das tecnologias digitais apresenta não significa falta de mudanças. Ao contrário, quando as inserimos em nossas ações docentes, percebemos seu potencial ilimitado e a diferença (transformações) que ocorre no dia a dia com os alunos.

Muitas vezes, imersos na cultura docente oriunda da formação inicial e repleta de saberes experienciais adquiridos no âmbito da profissão (TARDIF, 2014), o professor não se apercebe porque seu fazer está desencantado. O dar-se conta sobre as práticas pedagógicas que adotamos pode ser um processo que emerge somente quando buscamos compreender nosso processo de formação e/ou quando questionamos e buscamos soluções para os problemas emergentes no devir de nossa ação docente.

A aprendizagem para o uso dos artefatos, pelos educadores, deu-se pela própria necessidade do seu uso no dia a dia. Os professores relatam não conseguirem mais viver sem o auxílio destas ferramentas, e que, mesmo vivendo em uma cultura digital, em que aprendem pela necessidade do uso, ainda sentem a falta de formação específica para que possam utilizar as tecnologias digitais como ferramentas potencializadoras em seu fazer docente.

Pelo DSC1, é possível inferir que uma cultura docente para o uso dos recursos tecnológicos digitais organiza-se e toma sentido. No discurso, os entrevistados indicam que algumas dessas ferramentas fazem parte de seu fazer, como a busca por novas fontes de consulta, que antes ficavam restritas às bibliotecas físicas e aos livros didáticos adotados pela escola. 
Hoje, a ação de pesquisar extrapola os muros da escola e das casas e invade o ciberespaço, o que também é reafirmado no discurso coletivo, quando se expressa: "Gosto de pesquisar na internet; e sempre que necessito de informações rápidas, busco-as através deste mecanismo" (DSC 1). Com a internet, "é possível ter acesso a fontes de informação muito mais diversificadas que no passado e na medida também em que todos podem se exprimir para um vasto público" (LÉVY, 2015).

As mídias são assim, de fato, desterritorializadas, sem que isso signifique uma perda ou dissolução da dimensão local na produção de conteúdos. Elas não estão mais ligadas apenas a uma zona geográfica, mas a uma comunidade de proximidade local ou semântica, a redes sociais de ouvintes, de espectadores, de leitores ou de produtores, que podem estar dispersos e situados em qualquer lugar do mundo. (LÉVY; LEMOS, 2010, p. 74).

O DSC1 faz referência à socialização de conhecimentos em uma esfera pública que não fica mais restrita aos cadernos ou espaços da escola, pois indica que os professores de Matemática encontraram na web um lugar para divulgar ou compartilhar seus trabalhos.

Para Lévy e Lemos (2010), o uso de computadores conectados à internet possibilita acessar outras tecnologias como canais de televisão, estações de rádio e jornais online, bem como a potência de mídias independentes como os blogs e as redes sociais, especialmente o Facebook. Estas mídias atualmente ocupam um espaço significativo, por serem ferramentas que permitem processos de colaboração e conversação.

O DSC1 expressa uma cultura docente em ação na qual os professores aprendem a usar a tecnologia no dia a dia pela necessidade de seu uso, por interpretarem sua profissão como uma atividade de formação dos sujeitos do século XXI. Ao se perceberem sujeitos imersos na cultura digital, são capazes de a compreender e orientála de acordo com a necessidade para criar espaços de aprendizagem propícios ao desenvolvimento dos alunos em todas as suas dimensões.

\section{O USO PEDAGÓGICO DAS TECNOLOGIAS DIGITAIS}

Falar em uso pedagógico é indicar distintas possibilidades metodológicas que constituem o campo dos saberes e dos fazeres dos professores. Identificar metodologias capazes de provocar situações de aprendizagens mediatizadas pelo uso das tecnologias digitais requer uma (re)organização de saberes e fazeres, que pode ser uma tarefa bastante complicada, mas também faz surgir a constituição de uma cultura docente configurada pela própria ação. 
Para Tardif (2014), a noção de saber tem um sentido bastante amplo, que agrega os conhecimentos e as competências, o saber ser e o saber fazer, os quais precisam adequar-se às necessidades individuais e coletivas de todos os sujeitos envolvidos no processo educativo. O discurso coletivo "O uso pedagógico das tecnologias digitais" apresenta como os professores apropriaram-se dos conhecimentos tecnológicos e como fazem uso dos mesmos em seu fazer docente, entendendo-as como ferramentas potencializadoras dos processos de ensinar e aprender.

Entendo que é emergente o professor se inteirar a respeito do ensino potencializado pelas tecnologias, porém, considero importante que o mesmo avalie cada escolha metodológica levando em consideração as atividades a serem desenvolvidas em interface com o perfil dos alunos, e a comunidade escolar a qual está inserido. Entretanto, para nos apropriarmos das tecnologias digitais é necessário estarmos abertos para o desafio de aprender com o outro, uma vez que se o docente entender que conbecimento colaborativo pode ser construido de outras maneiras, ele fará uso dessa outra possibilidade e buscará maneiras para desenvolver um trabalho adequado a este entendimento e utilizará as tecnologias digitais de maneira que contribuam para esta construção. Além disso, o professor necessita estar em constante atualização, buscar sempre adequar sua formação e ir em busca de aprimoramento para suas aulas. Nesta caminhada, alunos e professores estarão juntos em um trabalho de descoberta, aprendizagem, ousadia e coragem, pois em determinados momentos o professor será amparado pela atualização digital que fazparte da vida dos alunos enquanto esses poderão precisar do apoio pedagógico e conceitual. O uso da tecnologia demanda a articulação com outros saberes, que nem sempre são valorizados e contemplados pelo currículo escolar. Acho que o professor tem que querer aprender novas metodologias, conhecer esse universo que está presente cada vez mais próximo dos nossos estudantes, legitimar a cultura digital e desejar fazer parte dela assim como qualquer cultura. Sem querer jamais qualquer educador irá entrar nesse mundo.

DSC 2 - 0 uso pedagógico das tecnologias digitais

O discurso expressa a necessidade de aquisição de conhecimentos sobre o uso das tecnologias digitais para criar novas formas de potencializar o trabalho docente. Evidencia a necessidade de um processo constante de formação para a aquisição ou atualização dos saberes vinculados ao trabalho com as tecnologias digitais. $\mathrm{O}$ trabalho mediatizado pelo uso das tecnologias digitais, portanto, necessita ser aliado ao uso de propostas metodológicas capazes de 
ampliar as ações dos professores e criar ambientes de aprendizagens significativos que favoreçam a autonomia, a criticidade e a reflexão sobre as experiências que vivem (RODRIGUES, 2007).

A necessidade de aliar uma proposta metodológica está presente nos discursos mostrando que os professores conhecem e compreendem a cultura que funda o espaço educativo, para identificar fatores que auxiliem o processo de significação pedagógica.

Seriam estes saberes os saberes experienciais? Parece-nos que sim, uma vez que estes saberes só serão reconhecidos quando os professores se manifestarem e puderem expressar suas ideias acerca dos demais saberes (curriculares e disciplinares), além dos saberes que determinam sua própria formação (TARDIF, 2014).

De acordo com Sancho (2006), as tecnologias digitais passaram a ser uma nova oportunidade para que os interessados possam usá-las como ferramentas para melhorar a qualidade da educação. A autora indica ainda que o fracasso gerado pelo não cumprimento das promessas tecnológicas deve-se à falta de um melhor planejamento no processo de integração do uso das tecnologias no ensinar e no aprender. Portanto, para que as mesmas possam representar uma forma de se mudar a educação, devemos mudar algumas coisas, tanto por parte dos professores e da equipe pedagógica como por parte da própria sociedade.

Mudar alguma coisa em relação ao professor significa modificar a própria ação, o que tem consequência imediata nos processos de formação docente, quer inicial, quer continuada. Porém, qualquer mudança implica diretamente sobre nossa reflexão: tal atitude expõe nossa ação sobre uma determinada emoção e assim, nossa vontade de querer ou não querer modificar o que já existe. Ou seja: mudar uma cultura predeterminada depende de nossos desejos.

Consequentemente, para que haja a possibilidade de uma mudança cultural, devemos compreender que isso exige também uma mudança emocional, e as coordenações de ações poderão se modificar, surgindo assim uma nova cultura (MATURANA, 2009, 2011). Ao aliarmos distintas tecnologias em nosso fazer docente, inserimo-nos em outras culturas pedagógicas, e essa possibilidade nos permitirá trazer a constituição de uma cultura docente em ação com maior possibilidade de se estabelecer, pois será oriunda da experiência e da reflexão sobre a ação.

A formação do professor para o uso das tecnologias digitais implica assim, (re)adequar suas práticas, uma vez que, com a diversificação de tecnologias e o acesso a elas, estas não podem mais serem ignoradas, cabendo a nós utilizá-las por meio de 
metodologias educativas que contemplem o processo de interação e, consequentemente, a construção do conhecimento. Com seu uso, deveremos ser capazes de criar espaços de convivência em que educadores e educandos transformam-se de forma congruente, ou seja, transformem-se na convivência de forma correspondente, harmônica e em concordância (MATURANA, 1993).

Esta transformação na convivência - uma convivência que pode ser instaurada não mais apenas no tempo real e único, mas também na confluência de outros tempos ampliados e distintos (LÉVY; LEMOS, 2010) - implica a construção de um espaço de colaboração entre todos os sujeitos envolvidos no processo educacional, como podemos observar no excerto do discurso:

[...] para nos apropriarmos das tecnologias digitais é necessário estarmos abertos para o desafio de aprender com o outro, uma vez que se o docente entender que conhecimento colaborativo pode ser construído de outras maneiras, ele fará uso dessa outra possibilidade e buscará maneiras para desenvolver um trabalho adequado a este entendimento e utilizará as tecnologias digitais de maneira que contribuam para esta construção (DSC 2).

Aprender com o outro é aprender na cooperação, e só há cooperação quando existe uma aceitação mútua, quando aceitamos o outro como legítimo outro na convivência. Entretanto, só há aceitação do outro como legítimo outro na convivência quando esta relação é fundada por uma emoção, a qual denominamos amor. Esta é a emoção na qual se funda um domínio de ações recorrentes (MATURANA, 2009).

Ao se assumirem como seres que cooperam, por meio de seus saberes, para a formação dos alunos, também aprenderão a (re)significar seus fazeres na convivência: "[...] em determinados momentos o professor será amparado pela atualização digital que faz parte da vida dos alunos enquanto esses poderão precisar do apoio pedagógico e conceitual" (DSC2).

Compreender que sua tarefa é ser um articulador no processo de aprendizagem poderá permitir ao professor a construção de práticas pedagógicas cooperativas que sejam capazes de fortalecer o processo de autonomia e criticidade dos sujeitos envolvidos. Como afirmam no fragmento do discurso, "Nesta caminhada, alunos e professores estarão juntos em um trabalho de descoberta, aprendizagem, ousadia e coragem[...]" (DSC2).

Quando expressaram que necessitavam "[...] legitimar a cultura digital e desejar fazer parte dela assim como qualquer cultura. Sem querer jamais qualquer educador irá entrar nesse mundo" (DSC2), 
mostraram entender as tecnologias digitais como ferramentas que podem auxiliá-los em seu fazer com uma carga afetiva do querer, visto que, se não houver vontade, não será possível a constituição de outra cultura.

Para Maturana (2009), o não querer fazer é o lado oculto da emoção que expressamos ao afirmar que não sabemos fazer alguma coisa, ou seja, podemos dizer que não sabemos usar as tecnologias digitais em nosso fazer pedagógico, entretanto, por trás disso, o que está oculto na emoção do não saber é a emoção de não estar motivado a fazer, a emoção de não querer mudar, de não querer aprender.

\section{O POTENCIAL DAS TECNOLOGIAS DIGITAIS PARA APRENDIZAGENS COOPERATIVAS}

Com os avanços proporcionados pelas tecnologias digitais, é perceptível que outros espaços de aprendizagem são criados para atender à necessidade dos sujeitos que buscam aprender. Estes espaços, especificamente os espaços virtuais, como os blogs e as redes sociais, possibilitam o diálogo, em tempo síncrono ou assíncrono, e permitem, de forma mais simples e menos constrangedora, dar voz a todos os sujeitos, onde eles estiverem, desde que possuam acesso à internet.

Assim, o diálogo favorecido pelas tecnologias digitais assume um importante papel quando utilizado de forma pedagógica, uma vez que possibilita discussões que podem despertar aprendizagens cooperativas, através do diálogo, das interações e do compartilhamento dos relatos que envolvem as experiências de cada sujeito.

Para compreendermos o processo de aprendizagem nos espaços educativos, potencializado pelo uso das tecnologias digitais, trazemos para o conversar o terceiro discurso coletivo, denominado "O potencial das tecnologias digitais para aprendizagens colaborativas - DSC3".

As tecnologias digitais como ferramentas potencializadoras da aprendizagem só serão efetivas quando o professor fizer uso destas como uma ferramenta do seu cotidiano, presente no seu planejamento como o livro, quadro, giz entre outros artefatos. Acredito que sua maior potencialidade está na possibilidade de trabalharmos o conhecimento em sua forma complexa, como se apresenta em nosso cotidiano e não de forma fragmentada. Vejo a tecnologia com um mediador do processo de aprendizagem quando está à disposição dos envolvidos e não quando são tratadas como a solução para todos os problemas escolares. Penso que estes artefatos precisam estar inseridos no contexto da ação e não simplesmente serem usados apenas para motivar a aprendizagem do aluno. Reconheço que os artefatos tecnológicos potencializam os espaços para a participação efetiva dos 
alunos quando objetivam propiciar a construção, reflexão, socialização de saberes e aprendizagens tanto de alunos quanto de professores quando são incorporados a uma ação pedagógica. Vejo a tecnologia com um meio de aproximação dos professores com os alunos quando estes assumirem a postura de articuladores, com a qual parem de acreditar que são o centro da educação. Alunos e professores podem agir de maneira em que ambos são sabedores de alguma coisa e ao mesmo tempo aprendentes de tantas outras. A colaboração exige que todos os envolvidos no processo sejam capazes de aprender em comunhão, necessita existir um espaço de respeito mútuo em que ambos possam aprender e ensinar. Além disso, torna o processo de aprendizagem imprevisivel, visto que poderá tomar dimensões e contemplar saberes não esperados, nem pelo professor e nem pelo aluno, proporcionado aprendizagens a ambos os sujeitos.

DSC3 - 0 potencial das tecnologias digitais para aprendizagens cooperativas

Neste discurso coletivo, encontra-se expresso que o uso das tecnologias digitais só será capaz de potencializar as práticas pedagógicas dos professores a partir do momento em que estes artefatos estejam presentes em seu cotidiano, especificamente, em seu planejamento, como estão o quadro e o livro didático.

$\mathrm{O}$ discurso indica ainda que, para as tecnologias digitais se fazerem presentes no planejamento, é importante a organização das ideias no que se refere aos conteúdos a serem trabalhados, às técnicas de ensino que serão adotadas e, especificamente, à seleção dos materiais que podem ser utilizados. O planejamento assume a condição transitória e pode a qualquer momento sofrer alterações, tendo em vista a necessidade de adequação das práticas ao longo do ano letivo.

Para Tardif e Lessard (2013, p. 214), por mais minucioso que seja um planejamento, muitas vezes é necessário alterá-lo, porque as coisas raramente acontecem como previstas e "no fim das contas, o planejamento não passa de um mapa geográfico do ensino; portanto, é normal que, em contato com o território real do trabalho, esse mapa seja modificado, especificado, adaptado.".

Planejar atividades usando as tecnologias digitais, nos espaços educativos, implica conhecer os processos de interação e mediação que podem ser potencializados por eles. Chats, correios eletrônicos, ambientes virtuais de aprendizagem ou mesmo as redes sociais podem se tornar ferramentas pedagógicas importantes para o ensinar e o aprender.

Por meio da troca de mensagens e de textos, alunos e professores planejam atividades a serem realizadas e ainda registram tudo o que foi produzido e discutido. Entretanto, este tipo de produção cooperativa requer que os participantes mantenham sua correspondência atualizada ou se façam presentes com frequência 
nos espaços em que compartilham o trabalho. Ao mesmo tempo, trabalhar nos espaços digitais não exige a sincronização de tempo entre alunos e professores, além de permitir a análise do registro de tudo que foi produzido e discutido e a verificação de como foi a participação do grupo. Para Assmann (2005, p. 22), "um dos aspectos mais fascinantes da era das redes é a transformação profunda do papel da memória ativa dos aprendentes na construção do conhecimento.".

Marques Neto (2006, p. 62) também afirma que "somente o fato de registrar os processos de planejamento e concepção de uma atividade coletiva já demonstra que a tecnologia não é apenas uma ferramenta de apoio, pois cria novas condições de produção do trabalho escolar [...]". Ao usar uma ferramenta digital para o desenvolvimento de uma atividade, o professor tem acesso a tudo que foi produzido, pois existe o registro escrito, e isto permite-lhe rever, sempre que necessário, a evolução da aprendizagem.

$\mathrm{O}$ uso das tecnologias permite, assim, constituir uma rede que aprende de forma colaborativa, gerando uma cultura que se constitui pelas afinidades e que pode se modificar através do que é compartilhado, sem perder a singularidade de cada um que dela participa e contribui para a formação de uma inteligência coletiva (LÉVY, 2011). Para o autor (2014, p. 29), uma inteligência coletiva é "uma inteligência distribuída por toda parte, incessantemente valorizada, coordenada em tempo real, que resulta em uma mobilização efetiva das competências.".

$\mathrm{Na}$ perspectiva de uma inteligência coletiva, o processo de construção do conhecimento não é um ato isolado, mas uma ação cooperativa, que se constitui através dos processos de interação estabelecidos nas redes fechadas de conversação. No DSC3 encontramos indícios da constituição de uma inteligência coletiva que se favorece das tecnologias digitais para fortalecer os elos de interação e o compromisso com a disseminação dos conhecimentos socialmente construídos.

De acordo com o discurso coletivo, a autoridade em sala de aula não pode mais ser estabelecida de forma unilateral: ela agora é compartilhada, cabendo ao professor atuar como um articulador, ou seja, um gerenciador no processo de estabelecer as prioridades a serem buscadas. Ele não é mais aquele que dá a palavra final, mas aquele que estimula a contrapalavra, auxilia a filtrar informações e os conduz ao seu objetivo. Agir desta forma possibilita o estreitamento da relação entre alunos e professores, num processo de interações recorrentes, ou seja, "lidar com processos educativos nas tecnologias digitais é estar diante de singularidades construídas na e pela coletividade" (LOPES, 2005, p. 45). 
O que decorre desta convivência são aprendizagens geradas através das interações estabelecidas nestes espaços. Para Maturana (1993), esse é um processo de aquisição, adaptação e acomodação a uma nova circunstância, ou seja, é uma mudança estrutural do organismo em um processo de transformação congruente. Tal processo de transformação abre espaço a um processo de adaptação e acomodação, no qual o sujeito aprendeu na convivência a se adaptar ao meio através de suas interações.

Entender a aprendizagem como um processo de transformações recorrentes com o meio e por outros seres vivos é compreender que vivemos em um processo de cooperação. Maturana (2014, p. 222) afirma que "a origem do homo sapiens não se deu através da competição, mas sim através da cooperação, e a cooperação só pode se dar como uma atividade espontânea através da aceitação mútua, isto é, através do amor".

Estar na cooperação é entender que o silêncio não deve ser o caminho para a construção de uma didática que possibilite a inclusão dos recursos tecnológicos em sala de aula. Pais e escolas devem propiciar momentos de diálogo sobre o imaginário dos alunos quando utilizam os recursos tecnológicos, pois, na busca por conhecer o espaço cibernético em que transitam, não devemos ter medo de instaurar uma didática constituída da ideia de que todos somos alunos de forma recíproca na convivência estabelecida (OROFINO, 2006).

Quando afirmam no discurso coletivo que "sua maior potencialidade está na possibilidade de trabalharmos o conhecimento em sua forma complexa, como se apresenta em nosso cotidiano e não de forma fragmentada", os professores querem dizer que compreendem o uso das tecnologias digitais potencializando o seu trabalho de forma mais ampla e menos fragmentada. Entretanto, se entendem a potencialidade dos recursos tecnológicos, por que ainda encontramos a resistência para fazer destes uma constante em suas práticas cotidianas?

Mudar a cultura docente em ação pode ser a saída para romper com os temores advindos do desconhecido. Mas como romper com uma cultura? Essa quebra ocorre quando nos inserimos em outra cultura, na qual somos legitimados, e passamos a atuar e a vivenciar experiências e emoções que não nos permitirão mais voltar atrás. Para os professores de Matemática, colaboradores do estudo, o uso das tecnologias traz possibilidades que vão além do fator motivação, ou seja, que são ferramentas capazes de gerar aprendizagem e solucionar os problemas da escola, os professores nos mostram que se inserem em uma rede de conversações que valida as tecnologias digitais em seu interior. 
Adquirir a postura de articuladores, como a que encontramos no discurso coletivo dos professores, abre espaço a uma ação compartilhada, no qual alunos e professores conduzem as aulas de forma colaborativa. Alunos e professores passam a se responsabilizar pela forma de aprender e consequentemente passam a ser ativos neste processo. A cooperação, também presente nos outros discursos coletivos, reforça nossa concepção de que, na aceitação do outro como legítimo na convivência, ou seja, quando há respeito e aceitação mútua, haverá aprendizagem significativa.

Alunos e professores podem agir de maneira em que ambos são sabedores de alguma coisa e ao mesmo tempo aprendentes de tantas outras. A colaboração exige que todos os envolvidos no processo sejam capazes de aprender em comunhão, necessita existir um espaço de respeito mútuo em que ambos possam aprender e ensinar. (DSC3).

Pensar e agir deste modo rompe com as certezas, uma vez que rompe com a lógica do professor que ensina e do aluno que aprende, além de tornar os processos de ensinar e de aprender imprevisíveis. Surge, então, o espaço para a flexibilidade no planejamento e a imprevisibilidade das ações de uma sala de aula.

Se estivermos no caminho explicativo da objetividade entre parênteses, o planejado poderá sofrer alterações e acontecer de forma imprevisível. Haverá uma disposição corporal que evidenciará o emocionar de todos os envolvidos naquele determinado momento. Os professores mostram no discurso coletivo que a colaboração "[...] torna o processo de aprendizagem imprevisível, visto que poderá tomar dimensões e contemplar saberes não esperados, nem pelo professor e nem pelo aluno, proporcionado aprendizagens a ambos os sujeitos" (DSC3).

Tardif e Lessard (2013) também afirmam que o trabalho em sala de aula é dinâmico, sujeito a imprevistos, os quais, através das interações, provocam a necessidade por parte do professor de ajustar e reorganizar seus planejamentos. Desse modo, é preciso reconhecer que "[...] o processo de aprendizagem é um espaço aberto, constituído por conhecimentos que emergem de entrelaçamento de ações de exploração, investigação e construção de forma coletiva ou individual" (LOPES, 2005, p. 44).

Interações recorrentes produzem a aprendizagem, ou seja, ela é o fenômeno da transformação na convivência, e o aprender origina-se da mudança estrutural por meio da convivência social (MATURANA, 2010). 
No DSC3, observamos uma cultura docente em ação de sujeitos que ensinam e ao ensinar aprendem através do processo de cooperação. Na interação, valorizam o saber de cada envolvido, dão voz e constroem aprendizagens através da convivência, na aceitação do outro como legítimo outro. Nesta aceitação, não há uma única voz que orienta o processo educativo, um único detentor do conhecimento que necessita repassar o que sabe aos demais sujeitos. Há um coletivo que, por meio de interações recorrentes constituem um espaço de convivência cooperador no qual se aprende ensinando e se ensina aprendendo. Pode-se inclusive afirmar que existe um coletivo inteligente, que se organiza em redes de aprendizagem nas quais os professores definem seu modo de atuação no operar das relações estabelecidas no espaço de aprendizagem.

\section{PARA NÃO ENCERRAR, CONTINUAMOS O CONVERSAR}

O estudo mostrou que as tecnologias digitais estão cada vez mais presentes nos espaços educativos, com potencial para transformar o ensinar e o aprender de forma significativa e os professores entendem e aceitam a sua chegada nas escolas, bem como a importância de usá-las pedagogicamente. Entretanto, seus discursos evidenciam a necessidade de uma maior apropriação técnica e um aprofundamento em propostas metodológicas que legitimem o seu uso.

O fato de olhar para os discursos coletivos, no caminho explicativo da objetividade entre parênteses, é tido por nós como uma possibilidade de entender a cultura dos professores de Matemática, porque neste caminho não existe algo independente do observador. Assim, não há uma única resposta capaz de definir a conduta de todos os professores de Matemática e desprezar as demais que possam surgir por outros observadores, mas sim evidenciar que muitas realidades existem.

O conversar teorizado possibilitou a construção de uma explicação sobre o fazer dos professores de Matemática que colaboraram com o estudo. Entrelaçando suas falas através dos discursos singulares, foi possível construir os discursos coletivos e teorizar sobre suas ações a fim de compreender sua experiência docente.

Nossa escolha pelos professores de Matemática, alunos ou egressos do PPGEC e atuantes em sala de aula, possibilitounos conhecer distintas realidades, visto que os colaboradores do estudo pertencem a distintas culturas docentes em ação, pois são professores que atuam na Educação Básica, no Ensino Superior e na 
Pós-Graduação. Embora pertençam a distintas realidades suas falas se engendraram e nos permitiram conhecer o que fazem e pensam através de um eu coletivizado que constituiu os discursos.

A escolha por estes professores representa a importância da formação continuada dos professores, uma vez que estar em um curso de pós-graduação possibilita a criação de espaços de reflexão sobre o seu fazer e a necessidade evidenciada por eles de permanecerem em redes de formação conhecendo e explorando diferenciadas metodologias de ensino atreladas ao uso das tecnologias digitais.

Uma cultura docente em ação se apresentou ou foram distintas culturas? O que aprendemos com este trabalho? Porque escolhemos conhecer a cultura docente em ação do professor de Matemática no uso dos recursos digitais? Aprendemos que nosso viver é constituído por diversas culturas, visto que transitamos por distintos espaços, com distintas pessoas que também transitam por espaços diferentes legitimando outras culturas. Aprendemos a aceitar o outro, a legitimar suas ações, entendendo e respeitando que os professores tenham dificuldade de usar as tecnologias digitais em seus ambientes de trabalho, mesmo sabendo que muitos deles as utilizam rotineiramente em suas vidas pessoais.

A pesquisa mostrou a possibilidade de abertura para mundos antes inatingíveis rompendo os muros fechados da escola, uma vez que por meio de computadores ligados à internet é possível conversar com alunos e professores virtualmente, legitimando a cultura digital como uma possibilidade de transformação na convivência. As redes sociais e os blogs fazem parte da vida dos alunos e dos professores e podem assumir um papel importante se utilizados pedagogicamente no planejamento, porque permitem a escrita compartilhada, a reflexão sobre a escrita, a reorganização das ideias, a socialização dos conhecimentos e a interação colaborativa.

Nos discursos coletivos os professores destacam a colaboração e a cooperação como ações que exigem que todos os envolvidos sejam capazes de aprender em comunhão, respeitando o outro como legítimo outro. Neste sentido, os recursos digitais são ferramentas importantes para potencializar espaços colaborativos, pois permitem a comunhão e a divergência de ideias, apresentação de pontos de vista e estratégias diferenciadas fazendo da sala de aula um espaço de compartilhamento de saberes.

Ao finalizarmos nosso conversar percebemos como o nosso olhar de observadores se modificou no processo de conversação que estabelecemos com os professores e passamos a entender o 
observador no caminho explicativo da objetividade entre parênteses (MATURANA, 2009) em um processo de interações recorrentes que nos possibilitou compreender que fazemos parte de um coletivo inteligente que se organiza em redes de conversação. Tais redes são definidoras e definem a cultura docente em ação na qual nos inserimos.

\section{REFERÊNCIAS}

ASSMANN, H. A metamorfose do aprender na sociedade do conhecimento. In: ASSMANN, H. Redes digitais e a metamorfose do aprender. Petrópolis, RJ: Vozes, 2005. p. 13-32.

BETTEGA, M. H. A educação continuada na era digital. São Paulo: Cortez, 2004. (Coleção questões da nossa época; v. 116).

LANKShear C; KNOBEL M. Pesquisa Pedagógica: do projeto a implementação. Porto Alegre, RS: Artmed, 2008.

LEFÈVRE F; LEFÈVRE, A. M. Discurso do Sujeito Coletivo: um novo enfoque em pesquisa qualiquantitativa (Desdobramentos). 2. Ed. Caxias do Sul, RS: Educs, 2005a. 256 p. (Coleção Diálogos).

LEFÈVRE F; LEFÈVRE, A. M. Depoimentos e discursos: uma proposta de análise em pesquisa social. Brasília: Líber Livro Editora, 2005b.

LEFÈVRE F; LEFÈVRE, A. M. Pesquisa de representação social: um enfoque qualiquantitativo: a metodologia do Discurso do Sujeito Coletivo. Brasília: Líber Livro Editora, 2010.

LEFÈVRE F; LEFÈVRE, A. M. Os novos instrumentos no contexto da pesquisa qualitativa. In: LEFÈVRE, F; LEFÈVRE, A. M. C; TEIXEIRA. J. J. V. (org.). O discurso do sujeito coletivo: uma nova abordagem metodológica em pesquisa qualitativa. Caxias do Sul, RS: Educs, 2000. p. 11-36.

LÉVY, P. Pierre Lévy: a revolução digital só está no começo. [14 de abril, 2015]. Porto Alegre: Jornal Correio do Povo. Entrevista concedida a Juremir Machado da Silva.

LÉVY, P. A esfera semântica. Tomo 1: computação, cognição e economia da informação. São Paulo: Annablume, 2014.

LÉVY, P. A inteligência coletiva. 8ª ed. São Paulo: Edições Loyola Jesuítas, 2011.

LÉVY, P.; LEMOS, A. O futuro da internet. São Paulo: Paulus, 2010.

LOPES, R. P. Um novo professor: novas funções e novas metáforas. In: ASSMANN, H. Redes digitais e a metamorfose do aprender. Petrópolis, RJ: Vozes, 2005. p. 33-55.

MARQUES NETO, H. T. A tecnologia da informação na escola. In: COSCARELLI, C. V. (org.). Novas tecnologias, novos textos, novas formas de pensar. $3^{\mathrm{a}}$ ed. Belo Horizonte, MG: Autêntica, 2006. p. 51-64.

MATURANA H. R. A ontologia da realidade. $3^{\mathrm{a}}$ ed. Belo Horizonte: Ed. UFMG, 2014. 
MATURANA H. R. Emoções e linguagem na educação e na política. Belo Horizonte: Ed. UFMG, 2009

MATURANA H. R. Cognição, ciência e vida cotidiana. Belo Horizonte: Ed. UFMG, 2001. MATURANA H. R. Uma nova concepção de aprendizagem. In: Dois pontos, v. 2, nº 15, 1993.

MATURANA H. R. Conversações matrísticas e patriarcais. In: MATURANA, H; VERDENZOLLER, G. Amar e brincar: fundamentos esquecidos do humano. $3^{\text {a }}$ ed. São Paulo: Palas Athena, 2011. p. 29-115.

MATURANA, H; VARELA, F. A árvore do conhecimento: as bases biológicas da compreensão humana. $8^{\text {a }}$ ed. São Paulo: Palas Athena, 2010.

OROFINO, M. I. Mídias e educação escolar: pedagogia dos meios, participação e visibilidade. São Paulo: Cortez, 2005.

PABLOS, J. A visão disciplinar no espaço das tecnologias da informação e comunicação. In: SANCHO, J. M.; HERNÁNDEZ, F. (org.). Tecnologias para transformar a educação. Porto Alegre: Artmed, 2006. p. 63-83.

RODRIGUES, S. C. Rede de conversação virtual: engendramento coletivo-singular na formação de professores. 2007. 150p. Tese (Doutorado) - Programa de Pós-Graduação em Informática na Educação, Universidade Federal do Rio Grande do Sul, Porto Alegre, 2007.

SANCHO, J. M. De tecnologia da informação e comunicação a recursos educativos. In: SANCHO, J. M; HERNÁNDEZ, F. (org.). Tecnologias para transformar a educação. Porto Alegre: Artmed, 2006. p. 15-42.

TARDIF, M; LESSARD, C. O trabalho docente: elementos para uma teoria da docência como profissão de interações humanas. Petrópolis, RJ: Vozes, 2013.

TARDIF, M. Saberes docentes e formação profissional. 16ª ed. Petrópolis, RJ: Vozes, 2014.

THURLER, M. G. Inovar no interior da escola. Porto Alegre: Artmed, 2001.

\section{NOTAS}

1 Disponível em https://docs.google.com/forms/d/1L-XuDrJzxkOLYoXCe373xLUwdhpGLtVeWxRfYJbx_w/viewform

Submetido: $24 / 04 / 2017$

Aprovado: 06/12/2019

Contato:

Rodovia Dourados/Itahum, Km 12

Unidade II Caixa Postal 364

Dourados $\mid$ MS |Brasil

CEP 79.804-970 